\title{
The associations of temperament, character, anxiety, and specialty choice among sixth-year medical students: a cross-sectional study
}

\author{
Erhan Akinci ${ }^{1 \odot}$ \\ 'Canakkale Onsekiz Mart University, Faculty of Medicine, Department of Psychiatry, Canakkale - Turkey
}

\begin{abstract}
Objective: This study aimed to investigate the effects of anxiety, temperament, and character dimensions on the preferences of final-year medical students for postgraduate education.

Method: Participants were 161 students in a sixth-year medical class. The primary outcome variables of the study were the preferred main specialty category and branch. Independent study variables were age, gender, perception of the economic situation, place of birth, and State-Trait Anxiety Inventory and Temperament and Character Inventory scores. Results for 151 participants were analyzed.

Results: The mean $( \pm S D)$ age of the participants was $23.66 \pm 1.18$ years, and $57.6 \%(n=87)$ were females. The participants stated that they would choose mostly internal $(64.2 \%, \mathrm{n}=97)$ and surgical $(35.1 \%, \mathrm{n}=53)$ disciplines, while the basic sciences were the least favored $(0.7 \%, n=1)$. The most popular specialties were psychiatry $(9.9 \%, n=15)$, orthopedics and traumatology $(8.6 \%$, $n=13)$, and physical therapy and rehabilitation $(8.6 \%, n=13)$. There was no significant difference between state $(X 2=1.93$, $\mathrm{p}=0.382)$ and trait $(\mathrm{X} 2=2.31, \mathrm{p}=0.315)$ anxiety levels and the specialty category selections. Harm avoidance (HA), fear of uncertainty (HA2), shyness (HA3), fatigability (HA4), and sentimentality (RD1) scores of students opting for internal medicine were statistically higher than scores for surgical sciences $(p<0.05)$. In addition, the resourcefulness (SD3) scores of the aspiring internists were statistically lower than scores for surgery $(p<0.05)$.

Conclusion: Temperament and character have some degree of influence on the choice of specialty, whereas anxiety was shown not to have such an impact. These findings may be helpful to medical educators or career counselors in the specialty choice of medical students.
\end{abstract}

Keywords: Anxiety, character, medical education, medical specialties, temperament

\section{INTRODUCTION}

"Postgraduate medical education (PME) is defined as the phase of medical training where doctors, after having obtained a formal medical qualification, can develop additional competencies in a defined area of their choice" (1). In particular, the undergraduate period is a stage at which medical students begin to know themselves professionally, and thus they are directed to the specialty branch corresponding to their temperament and personality traits. A significant number of physicians who complete basic medical education choose to continue postgraduate medical training and specialize in a specific field. The rates of

How to cite this article: Akinci $\mathrm{E}$. The associations of temperament, character, anxiety, and specialty choice among sixth-year medical students: a cross-sectional study. Dusunen Adam The Journal of Psychiatry and Neurological Sciences 2020;33:170-179.

Correspondence: Erhan Akinci, Canakkale Onsekiz Mart University, Faculty of Medicine, Department of Psychiatry, 17020, Canakkale - Turkey E-mail: drerhanakinci@yahoo.com

Received: November 06, 2019; Revised: December 19, 2019; Accepted: February 18, 2020 
participation in the specialty examination in medicine, which is decisive in PME, indicate that physicians preference for PME is directed towards receiving a specialist education. The most important motivation for PME in Turkey is the desire for professional satisfaction and specialization; the ability to plan a career after graduation is another important factor $(2,3)$.

In recent years, a significant change in the choice of specialty exams in medicine has led to a noticeable variation in the minimum scores required for individual specialty branches. It is noteworthy that ratings for some basic science specialties, such as medical biochemistry and medical microbiology, are rising $(4,5)$. Professional ideals and career plans, working conditions, shift duty, medical responsibility, malpractice concerns, financial rewards, and the effects of workload on doctors' private lives are some of the factors affecting post-graduate specialty selection. However, nowadays factors such as financial return and comfort come to the forefront in the choice of specialty (6-8). Furthermore, it is reported that students' experiences in medical faculties have an effect on their preferences. The choice of specialty is determined by environmental factors as well as the predisposition of the person, gender, temperament, and character traits $(9,10)$.

Cloninger defines personality with two primary components: temperament and character (11). The temperament dimensions persistence, novelty seeking (NS), reward dependence (RD), and harm avoidance (HA) are essential characteristics that affect an individual's life plans and decisions. Temperament reflects the hereditary aspect of individual behavioral differences and preferences. Self-directedness (SD), cooperation, and self-transcendence (ST) define the dimensions of character. The character aspect of personality matures through personal, environmental, and socio-cultural processes (12). The analysis of personality traits that characterize students may elucidate a generalizable relationship with their specialty preferences. Using the Temperament and Character Inventory (TCI) could lead to the description of personality traits that characterize particular medical students and predict their success in performing the tasks entailed by different specialties (13).

Career psychologists have argued that career choice and personality interfere with each other. There is limited knowledge of personality profiles and how they are related to specialty choice (14). According to cognitive theory, anxiety can be explained as the tendency to overestimate the potential for danger.
Persons with anxiety disorders tend to imagine the worst possible scenario and avoid supposedly dangerous situations, such as crowds, heights, or social interaction (15). It was suggested that temperament traits may be related with adaptive roles, such as depressive traits increasing the sensitivity to suffering, cyclothymic traits being relevant to creativity, and hyperthymic traits being implicated in generally more active pursuits (16). The effects of anxiety on choosing specialties have not been examined.

Clarifying the factors that underlie the choice of specialties may provide a better understanding of students' preferences for a given specialty and may be helpful in the development of health education. Among these factors, the personality traits of medical students are important elements that cannot be ignored. We hypothesized that there could be an association of the temperament and characters of the candidates for specialty-training and the selected specialties.

This study aimed to investigate the effects of anxiety, temperament, and character dimensions on final-year medical students' preferences for postgraduate education. The results are expected to provide objective data that will increase the satisfaction of medical students in their specialty choice.

\section{METHOD}

\section{Study Design}

The study with a cross-sectional analytical design was conducted at Canakkale Onsekiz Mart University Faculty of Medicine between July 2018 and March 2019. Study reporting was done as per the STROBE guidelines (17). The study protocol was approved by the local ethics committee at Canakkale Onsekiz Mart University (No: 15-07-Date: July 25, 2018). Each participant signed an informed consent form in conformity with the Declaration of Helsinki.

\section{Setting}

Canakkale Onsekiz Mart University is located in the northwest of Turkey. It operates a tertiary-level hospital serving a population of around 750.000 people. Medical students receive three years of preclinical education, followed by two years of clinical clerkships and a one-year internship training. During the study, there were 161 students in the internship year and in total nearly 900 students enrolled in the medical school. In the internship year, most of the training was carried out uninterrupted in the hospital environment for 52 weeks. 


\section{Participants}

Participating students were members of the sixth-year medical class, defined as the internship year at Canakkale Onsekiz Mart University Faculty of Medicine. The intern trainees were visited in their workplaces, and all 161 students were invited to answer the study questions in an empty and silent room. Under the supervision of the project leader and researchers, the students completed the self-report research questionnaire. Five students refused to join, and two were excluded due to insufficient and unreliable data. The results for 151 participants were analyzed (Figure $1)$. The participation rate was $93.8 \%(151 / 161)$.

\section{Measures}

The data collection tool consisted of three parts: the Personal Data Form, State-Trait Anxiety Inventory (STAI), and the TCI. The primary outcome variables of the study were the preferred main specialty area, the favorite specialty branch, and reasons to choose a particular specialty. Independent study variables were age (years), gender, perception of the economic situation, place of birth, STAI scores, and TCI dimension scores.

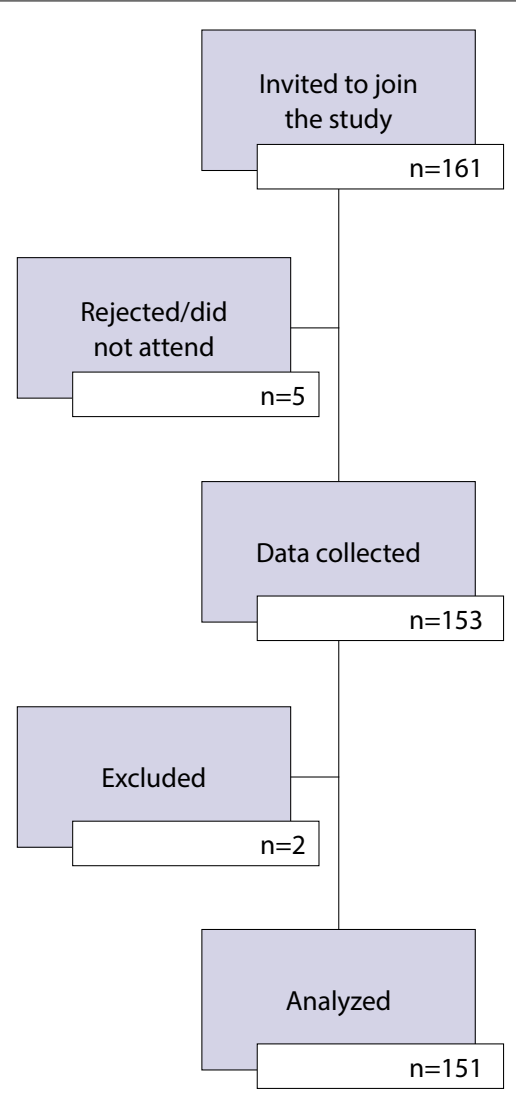

Figure 1. Study flow diagram.
State-Trait Anxiety Inventory: Developed by Spielberger et al. (18), it was designed to measure overall anxiety in adults on a four-point Likert-type scale (STAI Form X). In 1983, the STAI was revised to reduce the overlap with depression and emphasize better-described factors of state and trait anxiety (STAI Form Y) (19). The STAI is a psychological self-report inventory consisting of 40 questions. The STAI measures two types of anxiety - state anxiety, or anxiety about an event, and trait anxiety, or anxiety level as a personal characteristic. The scores obtained from both scales can range between 20 and 80 . Higher ratings indicate higher anxiety levels. The scores received from the scale were categorized as 1) <37 minimal anxiety, 2) 37-41 slight anxiety, and 3) $>41$ high anxiety. The scale was adapted and validated for the Turkish language by Oner and LeCompte (20). The values for reliability coefficients ranged between 0.26 and 0.68 for state anxiety and between 0.76 and 0.86 for trait anxiety.

Temperament and Character Inventory: Developed by Cloninger et al. (11), the TCI was designed to provide a comprehensive evaluation of normal personality and all its dimensions. The TCI includes statements for which the subject should select 'true' or 'false.' The TCI is a 240-item self-administered questionnaire constructed to assess personality in seven dimensions, divided into "temperament" and "character." Temperament is identified through the following four aspects: NS, HA, RD, and persistence (PS), while character is identified through the following three dimensions: SD, cooperativeness (C), and ST. The scale was adapted and validated for Turkish language by Kose et al. (12). Cronbach's alpha coefficients for the Turkish version of the TCI were reported to be between 0.60 and 0.85 in the temperament dimensions and between 0.82 and 0.83 in the character dimensions. Except for PS, all dimensions were subdivided into 3 to 5 subdimensions. In the temperament dimension, NS (Exploratory excitability [NS1], Impulsiveness [NS2], Extravagance [NS3], Disorderliness [NS4]), and HA (Anticipatory worry [HA1], Fear of uncertainty [HA2], Shyness [HA3], Fatigability [HA4]) have 4 subscales, and RD (Sentimentality [RD1], Attachment [RD2], Dependence [RD3]) has 3 subscales. In the character dimension, SD (Responsibility [SD1], Purposefulness [SD2], Resourcefulness [SD3], Self-acceptance [SD4], Enlightened second nature [SD5]), and C (Social acceptance [C1], Empathy [C2], Helpfulness [C3], Compassion [C4 ], Pure-hearted conscience [C5]) have 5 subscales and ST (Self-forgetful [ST1], Transpersonal identification [ST2], Spiritual acceptance [ST3]) has 3 
subscales. The scale scores consist of the sum of the subscale scores. For example, the T total NS score is calculated as (NS1+NS2+NS3+NS4).

\section{Bias}

The questionnaire included brief information about the research to ensure that the study data were obtained correctly, and participants were asked not to record their identities on the questionnaire form. To prevent bias, data collection was done by anonymous selfreporting, and error checking and debugging were made after entering the data into the computer.

\section{Statistical Analysis}

Data were digitized and analyzed using SPSS Statistics version 25.0 (Armonk, NY: IBM Corp.). The results were presented as frequencies, percentages, means, and standard deviations (SD). Normal distribution of the numerical data was analyzed using the KolmogorovSmirnov test. Homogeneity of variance was examined by Levene's test. For the comparison of the preferred main specialty sections, which were internal medicine and surgery, independent samples Student's t-test was used for TCI dimensions and sub-dimensions, as well as

\begin{tabular}{lcc} 
Table 1: Basic characteristics of the participants & \\
Variable & n & (\%) \\
\hline Sex & & \\
$\quad$ Female & 87 & 57.6 \\
$\quad$ Male & 64 & 42.4
\end{tabular}

Place of birth (province)*

$\begin{array}{lcc}\text { Istanbul } & 24 & 16.7 \\ \text { Bursa } & 14 & 9.7 \\ \text { Duzce } & 13 & 9.0 \\ \text { Ankara } & 11 & 7.6 \\ \text { Balikesir } & 8 & 5.6 \\ \text { Canakkale } & 7 & 4.9 \\ \text { Erzurum } & 6 & 4.2 \\ \text { Izmir } & 5 & 3.5 \\ \text { Eskisehir } & 5 & 3.5 \\ \text { Other } & 51 & 35.4 \\ \text { rception of economic situation } & * * \\ \text { Possibility to spend comfortably } & & \\ \text { No problems } & 21 & 14.1 \\ \text { Slight difficulty with livelihood } & 74 & 49.7 \\ \text { Moderate subsistence difficulty } & 28 & 18.8 \\ \text { Intense livelihood difficulties } & 23 & 15.4 \\ & 3 & 2.0\end{array}$

SD: Standard deviation, *: Data missing for 10 participants, **: Data missing for two participants the mean STAI scores. All hypotheses were two-sided, and a $\mathrm{p}$ value of $<0.05$ was considered statistically significant.

\section{RESULTS}

\section{Participants}

The study included 151 intern trainees. The mean $( \pm \mathrm{SD})$ age of the participants was $23.66 \pm 1.18$ years, and $57.6 \%(n=87)$ were females. The participants were born mostly in Turkey's most populous cities such as Istanbul (16.7\%, $\mathrm{n}=24)$, Bursa (9.7, $\mathrm{n}=14)$, and Ankara (7.6\%, $\mathrm{n}=11)$, or locally in Canakkale and surroundings $(4.2 \%$, $\mathrm{n}=7)$. Nearly half of the intern trainees $(49.7 \%, \mathrm{n}=74)$ did not have economic problems, $18.8 \%(n=28)$ had slight livelihood difficulties. Sociodemographic variables of the intern trainees are presented in Table 1.

\section{Descriptive Data}

The majority of the intern trainees $(88.1 \%, n=133)$ wanted to continue PME, and more than half felt that PME was necessary. The most common reasons for requesting specialty training were occupational satisfaction $(43.6 \%, n=41)$ and career opportunities $(31.9 \%, \mathrm{n}=30)$, respectively (Table 2 ).

The majority of participants stated that they would choose internal $(64.2 \%, \mathrm{n}=97)$ and surgical $(35.1 \%, \mathrm{n}=53)$ disciplines, while the basic sciences $(0.7 \%, \mathrm{n}=1)$ were the

Table 2: Opinions of intern trainees about postgraduate education

Variable

n $\quad(\%)$

Thinking of continuing postgraduate training

Yes

No

Undecided

32.0

$15 \quad 9.9$

Thinking that postgraduate medical education is necessary

Yes

$94 \quad 62.3$

No

$41 \quad 27.2$

Undecided

$16 \quad 10.6$

Reasons for requesting specialty training in medicine

$\begin{array}{lcc}\text { Occupational satisfaction } & 41 & 43.6 \\ \text { Career opportunities } & 30 & 31.9 \\ \text { Prestige and status } & 9 & 9.6 \\ \text { Other } & 6 & 6.4 \\ \text { Family and environmental pressure } & 4 & 4.3 \\ \text { Financial gain } & 4 & 4.3\end{array}$


Table 3: Distribution of intern trainees' preferences for areas and branches of specialties

Variable

n $\quad(\%)$

Preferred main specialty area

Internal Medicine

$97 \quad 64.2$

Surgery

$53 \quad 35.1$

Basic Medical Sciences

10.7

First preferred specialty

Psychiatry

Orthopedics and Traumatology

Physical Therapy and Rehabilitation

Ear, Nose, and Throat Diseases

Family Medicine

Dermatology

Gynecology and Obstetrics

Cardiology

Eye Diseases

Neurology

Internal Medicine

Chest Diseases

General Surgery

Radiology

Child and Adolescent Psychiatry

Emergency Medicine

Medical Genetics

Pediatrics

Plastic, Reconstructive and

Aesthetic Surgery

Neurosurgery

Anesthesiology and Reanimation

Nuclear Medicine

Infectious Diseases

Medical Pathology

Cardiac Surgery

Public Health

Medical Microbiology

Medical History and Ethics

Second preferred specialty

$\begin{array}{lcc}\text { Physical Therapy and Rehabilitation } & 16 & 12.0 \\ \text { Ear, Nose, and Throat Diseases } & 12 & 9.0 \\ \text { Internal Medicine } & 11 & 8.3 \\ \text { Neurology } & 8 & 6.0 \\ \text { Family Medicine } & 8 & 6.0 \\ \text { Eye Diseases } & 7 & 5.3 \\ \text { Psychiatry } & 7 & 5.3\end{array}$

Table 3: Distribution of intern trainees' preferences for areas and branches of specialties

\begin{tabular}{lll} 
Variable & n & (\%) \\
\hline Gynecology and Obstetrics & 6 & 4.5 \\
Cardiology & 6 & 4.5 \\
Emergency Medicine & 6 & 4.5 \\
Cardiac Surgery & 4 & 3.0 \\
Infectious Diseases & 4 & 3.0 \\
Pediatrics & 4 & 3.0 \\
Medical Biochemistry & 4 & 3.0 \\
Neurosurgery & 3 & 2.3 \\
Anesthesiology and Reanimation & 3 & 2.3 \\
Medical Genetics & 3 & 2.3 \\
Medical Microbiology & 3 & 2.3 \\
Orthopedics and Traumatology & 2 & 1.5 \\
General Surgery & 2 & 1.5 \\
Dermatology & 2 & 1.5 \\
Plastic, Reconstructive, and & 1 & 0.8 \\
Esthetic Surgery & 1 & 0.8 \\
Chest Surgery & 1 & 0.8 \\
Radiology & 1 & 0.8 \\
Nuclear Medicine & 1 & 0.8 \\
Public Health & 1 & 0.8 \\
Chest diseases & 1 & 0.8 \\
Medical Pharmacology & 1 & 0.8 \\
Forensic Medicine & 1 & 0.8 \\
Physiology & 1 & 0.8 \\
Medical History and Ethics & 1 & 0.8 \\
Biophysics & 1 & 0.8 \\
Anatomy & & \\
\hline & &
\end{tabular}

least popular choice. The most requested specialties were psychiatry $(9.9 \%, \mathrm{n}=15)$, orthopedics and traumatology $(8.6 \%, \mathrm{n}=13)$, and physical therapy and rehabilitation $(8.6 \%, n=13)$. In case they could not be allocated to their favorite specialties, the participants' most common second choices were physical therapy and rehabilitation $(12.0 \%, \mathrm{n}=16)$, ear, nose, and throat diseases $(9.0 \%$, $\mathrm{n}=12)$, or internal medicine $(8.3 \%, \mathrm{n}=11)$ (Table 3$)$.

The first three among the main reason for choosing a specialty were compliance with temperament and character $(29.2 \%, \mathrm{n}=42)$, lifestyle suitability $(18.1 \%$, $\mathrm{n}=26)$, and working conditions $(14.6 \%, \mathrm{n}=21)$, respectively. The second and third reasons for specialty choice were similar (Table 4 ).

The mean $( \pm$ SD) STAI state and trait scores of the participants were $38.01 \pm 8.79$ and $42.28 \pm 8.84$. The 
Table 4: Distribution of specialty preference reasons for the intern trainees

Reasons

n (\%)

Main reason for choosing a specialty

Compliance with temperament and character

Lifestyle suitability

Working conditions

Job satisfaction

Open to development

Low risk and responsibility

Financial reasons

Placement exam scores

Career plans

Possibility to study abroad

Contact with patients

Second reason for choosing a specialty

Compliance with temperament and character

Lifestyle suitability

Job satisfaction

Working conditions

Reasons such as risk and responsibility

Career plans

Placement exam scores

Open to development

Financial reasons

Contact with patients

Possibility to study abroad

Other

Third reason for choosing a specialty

\begin{tabular}{|c|c|}
\hline Lifestyle suitability & 29 \\
\hline Working conditions & 19 \\
\hline $\begin{array}{l}\text { Compliance with temperament and } \\
\text { character }\end{array}$ & 15 \\
\hline Reasons such as risk and responsibility & 14 \\
\hline Financial reasons & 13 \\
\hline Placement exam scores & 12 \\
\hline Open to development & 12 \\
\hline Job satisfaction & 10 \\
\hline Career plans & 9 \\
\hline Possibility to study abroad & 6 \\
\hline Contact with patients & 3 \\
\hline Availability of positions after graduation & 2 \\
\hline
\end{tabular}

intern trainees' high state and trait anxieties were $31.1 \%$ $(\mathrm{n}=47)$ and $57.6 \%(\mathrm{n}=87)$ according to the STAI.

For the temperament dimensions of TCI, the mean $( \pm \mathrm{SD})$ values were as follows: NS $(19.35 \pm 5.09)$, HA

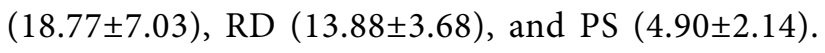
Character dimensions were as follows: SD $(29.88 \pm 6.93)$, C $(29.09 \pm 6.23)$, and ST $(15.60 \pm 6.14)$. The intern trainees' TCI dimension and sub-dimension scores are given in Table 5.

\section{Outcome Data}

Although 27 different specialty preferences were mentioned, the categories were merged into internal medicine and surgical disciplines during comparisons.

Using the STAI anxiety categories as dependent variable, the mean state and trait anxiety scores were compared using the independent samples t-test, which showed no significant difference between the groups. State anxiety scores for internal $(\mathrm{n}=95)$ and surgical $(n=52)$ disciplines were $38.55 \pm 8.98$ and $36.87 \pm 8.39$, respectively $(\mathrm{t}=1.110, \mathrm{p}=0.269)$. On the other hand, trait anxiety scores for internal $(n=93)$ and surgical $(n=49)$ areas were $43.05 \pm 9.01$ and $40.61 \pm 8.33$, respectively $(\mathrm{t}=1.574, \mathrm{p}=0.118)$.

Using the different mean TCI subscale scores as dependent variables, independent samples t-test was performed to compare between study preferences. HA (19.95 $\pm 6.89 \& 16.36 \pm 6.84)$, HA2 (4.69 $\pm 1.77 \& 3.62 \pm 2.03)$, HA3 (4.6 \pm 2.14 \& $3.67 \pm 2.08)$, HA4 (4.72 $\pm 2.26 \&$ $3.92 \pm 2.17)$ and $\mathrm{RD} 1(6.65 \pm 1.85 \& 5.92 \pm 1.85)$ scores of internal medicine were statistically higher than surgery scores $(\mathrm{p}<0.05)$. The SD3 $(3.23 \pm 1.28 \& 4.08 \pm 1.04)$ scores for internal medicine were statistically lower than scores for surgery $(\mathrm{p}<0.05)$. There was no statistical difference between the other TCI scale dimension and subdimension scores concerning the main medical specialty categories $(\mathrm{p}>0.05)$ (Table 6$)$.

\section{DISCUSSION}

The majority of intern trainees wanted to continue PME, and more than half felt that PME was necessary. The most common reasons for requesting specialty training were occupational satisfaction and career opportunities. On the other hand, only one participant (0.7\%) opted for basic medical sciences; all the other students chose internal or surgical disciplines. The most popular specialties were psychiatry, orthopedics and traumatology, and physical therapy and rehabilitation. The three most common answers to the question about the main reason for selecting a particular specialty were compliance with temperament and character, lifestyle suitability, and working conditions.

There was no statistically significant difference between state and trait anxiety levels and the selection 
Table 5: Intern trainees' TCI dimension and sub-dimension scores

\begin{tabular}{|c|c|c|c|c|}
\hline Dimension & Subscales & $\mathbf{n}$ & Mean & SD \\
\hline \multirow[t]{15}{*}{ Temperament } & Novelty seeking (NS) & 136 & 19.35 & 5.09 \\
\hline & Exploratory excitability (NS1) & 146 & 6.14 & 2.28 \\
\hline & Impulsiveness (NS2) & 143 & 3.78 & 2.33 \\
\hline & Extravagance (NS3) & 146 & 4.81 & 1.85 \\
\hline & Disorderliness (NS4) & 145 & 4.57 & 1.79 \\
\hline & Harm avoidance (HA) & 133 & 18.77 & 7.03 \\
\hline & Anticipatory worry (HA1) & 145 & 5.61 & 2.70 \\
\hline & Fear of uncertainty (HA2) & 148 & 4.32 & 1.93 \\
\hline & Shyness (HA3) & 140 & 4.28 & 2.15 \\
\hline & Fatigability (HA4) & 146 & 4.45 & 2.27 \\
\hline & Reward dependence (RD) & 137 & 13.88 & 3.68 \\
\hline & Sentimentality (RD1) & 146 & 6.38 & 1.87 \\
\hline & Openness to warm communication (RD2) & 143 & 4.31 & 1.92 \\
\hline & Attachment (RD3) & 146 & 3.02 & 1.52 \\
\hline & Persistence (PS) & 145 & 4.90 & 2.14 \\
\hline \multirow[t]{16}{*}{ Character } & Self-directedness (SD) & 131 & 29.88 & 6.93 \\
\hline & Responsibility (SD1) & 143 & 5.64 & 2.01 \\
\hline & Purposeful (SD2) & 148 & 5.83 & 1.80 \\
\hline & Resourcefulness (SD3) & 144 & 3.53 & 1.27 \\
\hline & Self-acceptance (SD4) & 145 & 5.39 & 2.79 \\
\hline & Enlightened second nature (SD5 & 141 & 9.50 & 2.00 \\
\hline & Cooperativeness (C) & 130 & 29.09 & 6.23 \\
\hline & Social acceptance (C1) & 142 & 6.20 & 1.76 \\
\hline & Empathy (C2) & 147 & 4.35 & 1.52 \\
\hline & Helpfulness (C3) & 149 & 4.72 & 1.31 \\
\hline & Compassion (C4) & 143 & 6.76 & 2.86 \\
\hline & Pure-hearted conscience (C5) & 143 & 7.00 & 1.57 \\
\hline & Self-transcendence (ST) & 128 & 15.60 & 6.14 \\
\hline & Self-forgetful (ST1) & 143 & 5.06 & 2.34 \\
\hline & Transpersonal identification (ST2) & 139 & 4.06 & 2.24 \\
\hline & Spiritual acceptance (ST3) & 136 & 6.62 & 3.35 \\
\hline
\end{tabular}

SD: Standard deviation

of the specialty fields. However, HA and RD1 scores for internal medicine were statistically higher than scores for surgical disciplines. The SD3 scores for internal medicine were statistically lower than those for surgery. There were no significant differences in the other TCI scale dimension and sub-dimension scores regarding the main medical specialty areas.

In our study, both trait and state anxiety levels were high (especially trait anxiety). In a systematic review, anxiety levels were reported to be higher among US and Canadian medical students than in the general population (21). In a study conducted in Egypt, the prevalence of anxiety among medical students was 73\% (22). The prevalence of anxiety was reported to be $32.9 \%$ in a systematic review and meta-analysis examining mental health problems among medical students in Brazil (23). A multicenter study using the STAI scale in medical students reported state-anxiety to be $81.7 \%$ and trait-anxiety to be $85.6 \%(24)$.

One of the reasons why intern trainees want to specialize in internal medicine departments rather than in surgical departments may be the high level of anxiety among residents who choose surgical disciplines (25). We could not find any Turkish or English publications 
Table 6: Comparison of the $\mathrm{TCl}$ scale and subscale scores according to medical specialty categories

\begin{tabular}{|c|c|c|c|c|c|c|c|c|}
\hline \multirow[b]{3}{*}{ Dimension } & \multicolumn{8}{|c|}{ Preferred main specialty area* } \\
\hline & \multicolumn{2}{|c|}{ Internal Medicine } & \multirow[b]{2}{*}{$\mathbf{n}$} & \multicolumn{2}{|c|}{ Surgical Disciplines } & \multirow[b]{2}{*}{$\mathbf{n}$} & \multirow[b]{2}{*}{$\mathbf{t}$} & \multirow[b]{2}{*}{$\mathbf{p}$} \\
\hline & Mean & SD & & Mean & SD & & & \\
\hline Novelty seeking (NS) & 19.30 & 5.18 & 86 & 19.47 & 5.01 & 49 & -0.18 & 0.856 \\
\hline Exploratory excitability (NS1) & 5.87 & 2.23 & 92 & 6.68 & 2.23 & 53 & -2.10 & 0.037 \\
\hline Impulsiveness (NS2) & 3.78 & 2.29 & 92 & 3.74 & 2.42 & 50 & 0.10 & 0.918 \\
\hline Extravagance (NS3) & 4.98 & 1.97 & 92 & 4.51 & 1.62 & 53 & 1.47 & 0.144 \\
\hline Disorderliness (NS4) & 4.62 & 1.85 & 93 & 4.45 & 1.71 & 51 & 0.55 & 0.584 \\
\hline Harm avoidance (HA) & 19.95 & 6.89 & 88 & 16.36 & 6.84 & 44 & 2.83 & 0.005 \\
\hline Anticipatory worry (HA1) & 5.82 & 2.70 & 94 & 5.28 & 2.67 & 50 & 1.15 & 0.253 \\
\hline Fear of uncertainty (HA2) & 4.69 & 1.77 & 95 & 3.62 & 2.03 & 52 & 3.35 & 0.001 \\
\hline Shyness (HA3) & 4.60 & 2.14 & 91 & 3.67 & 2.08 & 48 & 2.48 & 0.014 \\
\hline Fatigability (HA4) & 4.72 & 2.26 & 92 & 3.92 & 2.17 & 53 & 2.08 & 0.040 \\
\hline Reward dependence (RD) & 14.22 & 3.53 & 88 & 13.38 & 3.84 & 48 & 1.25 & 0.213 \\
\hline Sentimentality (RD1) & 6.65 & 1.85 & 94 & 5.92 & 1.85 & 51 & 2.26 & 0.026 \\
\hline Openness to warm communication (RD2) & 4.35 & 1.80 & 91 & 4.31 & 2.11 & 51 & 0.11 & 0.910 \\
\hline Attachment (RD3) & 3.13 & 1.43 & 93 & 2.85 & 1.66 & 52 & 1.08 & 0.283 \\
\hline Persistence (PS) & 4.73 & 2.09 & 94 & 5.30 & 2.17 & 50 & -1.53 & 0.128 \\
\hline Self-directedness (SD) & 29.61 & 7.48 & 84 & 30.59 & 5.71 & 46 & -0.77 & 0.441 \\
\hline Responsibility (SD1) & 5.51 & 2.11 & 93 & 5.96 & 1.73 & 49 & -1.29 & 0.199 \\
\hline Purposeful (SD2) & 5.76 & 1.84 & 95 & 6.04 & 1.68 & 52 & -0.91 & 0.363 \\
\hline Resourcefulness (SD3) & 3.23 & 1.28 & 91 & 4.08 & 1.04 & 52 & -4.05 & $<0.001$ \\
\hline Self-acceptance (SD4) & 5.46 & 2.93 & 91 & 5.23 & 2.55 & 53 & 0.49 & 0.627 \\
\hline Enlightened second nature (SD5 & 9.55 & 2.09 & 89 & 9.49 & 1.78 & 51 & 0.17 & 0.863 \\
\hline Cooperativeness (C) & 29.36 & 6.04 & 85 & 28.86 & 6.40 & 44 & 0.44 & 0.663 \\
\hline Social acceptance (C1) & 6.15 & 1.76 & 92 & 6.35 & 1.73 & 49 & -0.63 & 0.528 \\
\hline Empathy (C2) & 4.46 & 1.52 & 95 & 4.20 & 1.48 & 51 & 1.02 & 0.309 \\
\hline Helpfulness (C3) & 4.68 & 1.27 & 95 & 4.79 & 1.41 & 53 & -0.48 & 0.632 \\
\hline Compassion (C4) & 7.03 & 2.66 & 89 & 6.38 & 3.11 & 53 & 1.33 & 0.185 \\
\hline Pure-hearted conscience (C5) & 7.04 & 1.59 & 85 & 6.98 & 1.50 & 44 & 0.23 & 0.817 \\
\hline Self-transcendence (ST) & 15.60 & 6.51 & 84 & 15.61 & 5.45 & 44 & -0.02 & 0.987 \\
\hline Self-forgetful (ST1) & 5.08 & 2.39 & 93 & 5.04 & 2.28 & 50 & 0.09 & 0.932 \\
\hline Transpersonal identification (ST2) & 3.94 & 2.26 & 90 & 4.35 & 2.20 & 48 & -1.03 & 0.307 \\
\hline Spiritual acceptance (ST3) & 6.71 & 3.70 & 86 & 6.53 & 2.67 & 49 & 0.30 & 0.767 \\
\hline
\end{tabular}

SD: Standard deviation, *Basic medical sciences were not included in the analysis as there was only one selection

examining the effect of anxiety on specialty selection. Our study showed that the levels of state and trait anxiety did not affect the choice of the main areas of specialty.

Vaidya et al. (26) used the TCI scale to examine the relationship between the temperament and characteristics of medical students and the choice of specialty, finding students choosing surgery, emergency medicine, and obstetrics and gynecology to be higher in NS than the other students. The potential future surgeons were lower in HA and RD than the others. Students choosing primary care specialties, emergency medicine, and obstetrics and gynecology were all high in $\mathrm{RD}$, with students aiming at entering pediatrics having the highest scores.

Many studies have reported that the personality trait is a common intrinsic factor in the specialty choice (2729). Our findings suggest that temperament (HA and RD1) and character (SD3) influence specialty choice. $\mathrm{HA}$, associated with the neurotransmitter serotonin, is 
the tendency to avoid or give up certain behaviors as an intense response to aversive stimuli manifesting itself as fear of uncertainty, shyness of strangers, quick fatigability, and pessimistic worry of future problems. $\mathrm{RD}$, which is associated with the neurotransmitter noradrenaline, is a tendency towards intense response to reward, seen as sentimentality, social attachment, and dependence on approval of others. SD refers to selfdetermination, being able to control, regulate, and adapt behavior per own goals and values, to be self-sufficient, self-acceptant, responsible, reliable, and effective (30). In our study, students choosing surgery were as cooperative as the other students. However, Schwartz et al. (31) found surgeons to be especially high in $\mathrm{C}$ and $\mathrm{SD}$. There may indeed be a surgical personality characterized by extraversion, $\mathrm{C}$, and SD.

Some limitations of this study deserve mention. First, research was conducted in only one class of finalyear students at a single medical school during one academic year in Turkey. Therefore, it is difficult to generalize the findings. Second, this research did not closely examine other motivational factors such as lifestyles, beliefs, competitiveness, and duration of the residency program. Third, the data collection method bears the limitations of questionnaire studies. Finally, our sample is not large enough to analyze each specialty in detail. Since this was not a sampling study, a sample size calculation was not performed; the whole population was invited to join.

In conclusion, the present results suggest that temperament and character have some influence on specialty choice, whereas anxiety did not demonstrate such an impact. These findings may be beneficial to medical educators or career counselors for the specialty choice of medical students. Despite its limitations, this study may be helpful to medical students, professors, and medical educators in the process of specialty choice. Further research with larger sample sizes, including other grades of students, will be required to evaluate the more intricate factors associated with specialty choice.

\begin{tabular}{|c|c|c|}
\hline \multicolumn{2}{|c|}{ Contribution Categories } & Author Initials \\
\hline \multirow{3}{*}{ Category 1} & Concept/Design & E.A. \\
\hline & Data acquisition & E.A. \\
\hline & Data analysis/Interpretation & E.A. \\
\hline \multirow{2}{*}{ Category 2} & Drafting manuscript & E.A. \\
\hline & Critical revision of manuscript & E.A. \\
\hline Category 3 & Final approval and accountability & E.A. \\
\hline \multirow{2}{*}{ Other } & Technical or material support & $\mathrm{N} / \mathrm{A}$ \\
\hline & Supervision & $\mathrm{N} / \mathrm{A}$ \\
\hline
\end{tabular}

Ethics Committee Approval: The study protocol was approved by the local ethics committee at Çanakkale Onsekiz Mart University (No: 15-07-Date: 25.07.2018).

Informed Consent: Each participant signed an informed consent form following the Declaration of Helsinki.

Peer-review: Externally peer-reviewed.

Conflict of Interest: No conflict of interest.

Financial Disclosure: This study was not funded by any organization.

\section{REFERENCES}

1. Busari OJ, Duits A. Postgraduate medical education: In Walsh K (editor). Oxford Textbook of Medical Education. Oxford University Press, 2013, 1-20.

2. Bati H. Stages and characteristics of medical education: In Sayek I (editor). Medical Trainer Handbook. Ankara: Gunes Tip Kitabevleri, 2016, 29-42. (Turkish)

3. Goktas Dortyol B. Future thoughts and career choices of last year of medical faculty students and affecting factors. Tip Egitimi Dunyasi 2017; 16:12-21. (Turkish)

4. Kaya A, Akturk Z, Cayir Y, Tastan K. Medical specialization exams between 2007-2013: A trend analysis. Ankara Med J 2014; 14:53-58. (Turkish)

5. OSYM. TUS Evaluation Reports. https://www.osym.gov. tr/TR,14999/tus-degerlendirme-raporlari.html. Accessed September 1, 2019.

6. Tan MN, Ozcakar N, Kartal M. Resident doctors' professional satisfaction and its effect on their lives. Marmara Medical Journal $2015 ; 25: 20-25$.

7. Tekin C, Gunes G, Turkol E. Residency choices of medical students at Inonu University Medical Faculty and the factors to affect these choices. İnönü Üniversitesi Sağlık Bilimleri Dergisi 2013; 1:5-10. (Turkish)

8. Lefevre JH, Roupret M, Kerneis S, Karila L. Career choices of medical students: a national survey of 1780 students. Med Educ 2010; 44:603-612.

9. Goldacre MJ, Turner G, Lambert TW. Variation by medical school in career choices of UK graduates of 1999 and 2000. Med Educ 2004; 38:249-258.

10. Woolf K, Elton C, Newport M. The specialty choices of graduates from Brighton and Sussex Medical School: a longitudinal cohort study. BMC Med Educ 2015; 15:46.

11. Cloninger CR, Svrakic DM, Przybeck TR. A psychobiological model of temperament and character. Arch Gen Psychiatry 1993; 50:975-990.

12. Kose S, Sayar K, Ak I, Aydin N, Kalelioglu U, Kirpinar I, et al. Turkish version of the TCI: Reliability, validity, and factorial structure. Bulletin of Clinical Psychopharmacology 2004; 14:107131. (Turkish)

13. Borges NJ, Savickas ML. Personality and medical specialty choice: A literature review and integration. Journal of Career Assessment 2002; 362-380. 
14. Kosif R, Konuk N. Clonninger's temperament and character inventory profiles of anatomists: is there a relation with specialty choice? Bratisl Lek Listy 2016; 117):112-118.

15. Aikins DE, Craske MG. Cognitive theories of generalized anxiety disorder. Psychiatr Clin North Am 2001; 24:57-74.

16. Maremmani I, Dell'Osso L, Rovai L, Pacini M, Arduino G, Montagnari A, et al. TEMPS-A[p] temperament profile related to professional choice: A study in 1548 applicants to become a cadet officer in the Italian air force. J Affect Disord 2010; 124:314-318.

17. von Elm E, Altman DG, Egger M, Pocock SJ, Gøtzsche PC, Vandenbroucke JP; STROBE Initiative. The Strengthening the Reporting of Observational Studies in Epidemiology (STROBE) statement: guidelines for reporting observational studies. Ann Intern Med 2007; 147:573-577.

18. Spielberger CD, Gorsuch RL, Lushene RE. Manual for the StateTrait Anxiety Inventory (Self Evaluation Questionnaire). Palo Alto, CA: Consulting Psychologists Press Inc., 1970.

19. Spielberger CD, Gorsuch RL, Lushene R, Vagg PR, Jacobs GA. Manual for the State-Trait Anxiety Inventory. Palo Alto, CA: Consulting Psychologists Press Inc., 1983.

20. Oner N, Le Compte A. Manual for the State Trait Anxiety Inventory-Turkish form. Istanbul: Bogazici Universitesi, 1985. (Turkish)

21. Dyrbye LN, Thomas MR, Shanafelt TD. Systematic review of depression, anxiety, and other indicators of psychological distress among U.S. and Canadian medical students. Acad Med 2006; 81:354-373.

22. Fawzy M, Hamed SA. Prevalence of psychological stress, depression and anxiety among medical students in Egypt. Psychiatry Res 2017; 255:186-194.

23. Pacheco JP, Giacomin HT, Tam WW, Ribeiro TB, Arab C, Bezerra IM, et al. Mental health problems among medical students in
Brazil: a systematic review and meta-analysis. Braz J Psychiatry 2017; 39:369-378.

24. Brenneisen Mayer F, Souza Santos I, Silveira PS, Itaqui Lopes MH, de Souza AR, Campos EP, et al. Factors associated to depression and anxiety in medical students: a multicenter study. BMC Med Educ 2016; 16:282.

25. Marzouk M, Ouanes-Besbes L, Ouanes I, Hammouda Z, Dachraoui F, Abroug F. Prevalence of anxiety and depressive symptoms among medical residents in Tunisia: a cross-sectional survey. BMJ Open 2018; 8:e020655.

26. Vaidya NA, Sierles FS, Raida MD, Fakhoury FJ, Przybeck TR, Cloninger CR. Relationship between specialty choice and medical student temperament and character assessed with Cloninger Inventory. Teach Learn Med 2004; 16:150-156.

27. Jafrani S, Zehra N, Zehra M, Abuzar Ali SM, Abubakar Mohsin SA, Azhar R. Assessment of personality type and medical specialty choice among medical students from Karachi; using Myers-Briggs Type Indicator (MBTI) tool. J Pak Med Assoc 2017; 67:520-526.

28. Kwon OY, Park SY. Specialty choice preference of medical students according to personality traits by Five-Factor Model. Korean J Med Educ 2016; 28:95-102.

29. Fang JT, Lii SC. Relationship between personality traits and choosing a medical specialty. J Formos Med Assoc 2015; 114:1116-1121.

30. Garcia D, Lester N, Cloninger KM, Cloninger CR. Temperament and Character Inventory (TCI): In Zeigler-Hill V, Shackelford T (editors). Encyclopedia of Personality and Individual Differences. Cham, Switzerland: Springer, 2017, 1-3.

31. Schwartz RW, Barclay JR, Harrell PL, Murphy AE, Jarecky RK, Donnelly MB. Defining the surgical personality: a preliminary study. Surgery 1994; 115:62-68. 